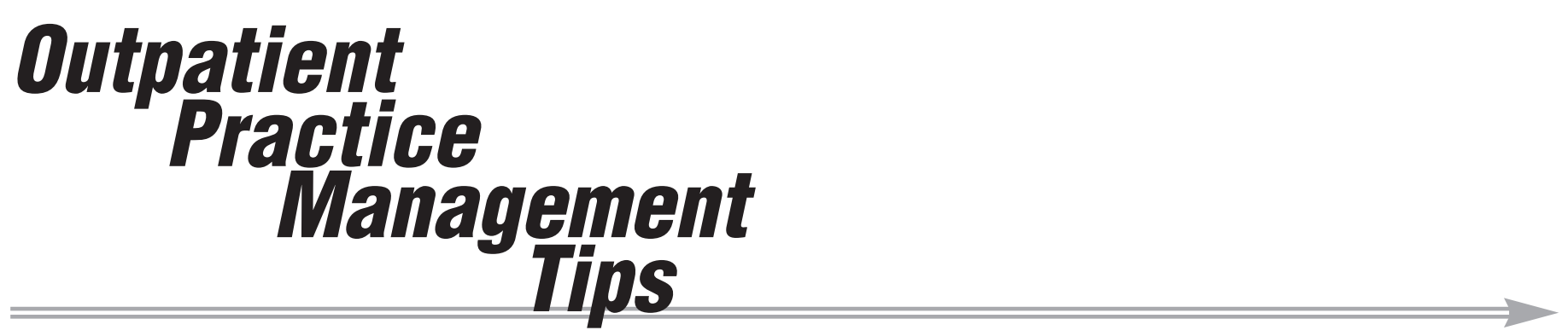

\title{
Tests of Liver Injury
}

\author{
Kenneth A. Musana, MD, Department of Internal Medicine, Marshfield Clinic, Marshfield, Wisconsin \\ Steven H. Yale, MD, Department of Internal Medicine, Marshfield Clinic, Marshfield, Wisconsin \\ Ahmad S. Abdulkarim, MD, Department of Gastroenterology, Marshfield Clinic, Marshfield, Wisconsin
}

\section{REPRINT REQUESTS:}

Steven H. Yale, MD

Department of Internal Medicine

Marshfield Clinic

1000 North Oak Avenue

Marshfield, WI 54449

Telephone: 715-387-5436

Fax: 715-389-3808

Email: yale.steven@marshfieldclinic.org

\section{KEYWORDS:}

Liver/pathology; Hepatitis C; Alanine transaminase; Serologic tests; Liver diseases; Liver function tests
Clinical Medicine \& Research

Volume 2, Number 2: 129-131

()2004 Clinical Medicine \& Research

http://www.mfldclin.edu/clinmedres
Liver test abnormalities are commonly found in ambulatory patients now that these tests are routinely included in chemistry panels. The majority of asymptomatic patients with liver test abnormalities have no evidence of liver disease. Recognizing the different patterns of liver injury can be used as a guide to direct further evaluation of diseases that affect the liver.

\section{Definition of the four patterns of liver injury and biochemical profiles found in each.}

A thorough understanding of the pattern and profiles of liver injury can provide clinicians with important clues into the mechanism of disease and underlying diagnosis. It is important to appreciate that this classification, although useful, is not restrictive since certain diseases (e.g., alcoholic hepatitis, viral hepatitis) or drugs can present with more than one pattern of liver injury. There are four major types of liver injury: hepatocellular, autoimmune, cholestatic, and infiltrative (table 1). The predominant laboratory abnormality defines the pattern of injury. A hepatocellular pattern is marked by isolated or predominant elevations of serum transaminases. The initial step in the evaluation of elevated transaminases should include a complete history in order to identify the most common causes of liver injury including alcohol, hepatitis B and C, celiac disease, hemochromatosis, and nonalcoholic steatohepatitis. Cholestatic and infiltrative patterns, in contrast, have elevation in serum alkaline phosphatase with normal or mild elevations in serum transaminases. Markedly elevated bilirubin levels found in cholestatic diseases further differentiate between cholestatic and infiltrative patterns. After confirming that the elevated alkaline phosphatase is of liver origin by using one of the following: 5 '-nucleotidase, $\gamma$-glutamyltransferase, leucine aminopeptidase, or fractionated alkaline phosphatase; an abdominal ultrasound should be performed. An ultrasound can be useful in determining whether there is an intrahepatic or extrahepatic cause of cholestatic pattern of liver injury. An autoimmune mechanism can present with either a hepatocellular pattern if the hepatocytes are involved (autoimmune hepatitis) or cholestatic if the immune mechanism targets the biliary ducts (e.g., primary biliary cirrhosis). ${ }^{1}$

Outline of the approach to evaluating an asymptomatic patient with mild isolated elevation in alanine transaminase (ALT).

Isolated elevation in ALT may be unexpectedly discovered in otherwise healthy blood donors or when laboratory tests are performed as part of a physical examination. Assessment of tests of liver injury should be approached in a stepwise and cost-effective methodological manner. It is important to define the "normal" range in order to understand and appreciate the significance of reference values assigned to all laboratory tests. 
Table 1. Common patterns of liver injury.

\begin{tabular}{lccc}
\hline & \multicolumn{3}{c}{ Autoimmune } \\
\hline & Hepatocellular & Cholestatic & Infiltrative \\
\hline Transaminases & $++/+++$ & $0 /+$ & $0 /+$ \\
Alkaline phosphatase & $0 /+$ & $++/+++$ & $++/+++$ \\
Bilirubin & $0 /+++$ & $0 /+++$ & $0 /+$ \\
\hline
\end{tabular}

Normal $=0$; degrees of abnormality $=+$ to +++ .

Adapted from Moseley. ${ }^{1}$

Laboratory values follow a distribution in that $95 \%$ of the "normal" population falls within two standard deviations above or below the mean value. Therefore, $2.5 \%$ of the normal population will have laboratory values that fall outside the upper and lower limits of normal. Normal ALT values vary depending upon other factors such as age, weight, time of day, and level of exercise. ${ }^{2-4}$ Additionally, it is important to consider laboratory error and to verify the test if the quality standards of the laboratory are in question.

All tests of liver injury are neither highly sensitive nor specific. Thus, it is imperative that the evaluation first confirms the result of an abnormal test by either repeating it and/or ordering a more specific one. In asymptomatic patients with mild elevations of transaminases (less than five times normal) or those with a low pretest probability of having liver disease, the abnormal laboratory test should first be confirmed. The interval at which to repeat the abnormal test in asymptomatic patients with mild disease has not been firmly established. Several studies have found that patients with elevations of ALT persisting longer than 6 months have a higher incidence of identifiable causes of liver disease.5,6 Persistently positive test results should lead to further inquiry into the mechanism(s) of liver injury (figure 1).

Initial evaluation of all patients with persistent ALT elevations should include a thorough and accurate history and physical examination. The history must include questions about family history of immune mediated and other inherited disorders, over the counter herbal and prescription drugs, high risk exposures or lifestyles including sexual history, illicit drugs, tattoos, transfusions, alcohol, occupation, travel, and obesity. Physical examination may be useful in providing clues to the chronicity of the liver disease. Discontinuation of all non-essential medications or potentially hepatotoxic medications and alcohol should be recommended and ALT levels remeasured. ${ }^{2}$

\section{Description of the best serologic method for diagnosing hepatitis $\mathrm{C}$ virus (HCV).}

$\mathrm{HCV}$ is a common cause of liver disease and hepatocellular carcinoma. In most cases this disease is characterized by a hepatocellular pattern of liver injury. Approximately one-third of those affected have normal transaminase levels. Thus, in patients with HCV, transaminases are less useful in determining the extent of liver injury. ${ }^{4}$

There are two main categories of tests for detecting HCV infection: tests for detecting antibodies (serology) and those for viral RNA (molecular-based) ${ }^{7}$ (table 2). Patients with a hepatocellular pattern of liver injury suggestive of $\mathrm{HCV}$ should undergo initial screening by the enzyme-linked immunosorbent assay (ELISA).

The recombinant immunoblot assay (RIBA) and ELISA share the same sensitivity. Compared to ELISA, RIBA has a higher specificity. Patients who react to two or more HCV antigens by RIBA are considered to have tested positive, while those who react to one antigen have indeterminate results. Both a positive ELISA and RIBA test do not

Table 2. Laboratory evaluation of hepatitis C.

\begin{tabular}{llll}
\hline Test & Sensitivity & Disadvantage & Clinical utility \\
\hline HCV-ELISA & $95 \%$ & $\begin{array}{c}\text { Window period of } 8 \text { to } 14 \\
\text { weeks } \\
\text { Does not distinguish } \\
\text { between past and } \\
\text { current infection }\end{array}$ & $\begin{array}{l}\text { Screening test } \\
\text { Easy to do } \\
\text { Low variability } \\
\text { Ease of automation }\end{array}$ \\
HCV-RIBA & $95 \%$ & $\begin{array}{l}\text { Technically demanding } \\
\text { Does not distinguish } \\
\text { between past and } \\
\text { current infection }\end{array}$ & Use to confirm positive \\
& & ELISA & \\
HCV-PCR & Technically demanding & Confirmatory test \\
qualitative & $96 \%$ to $100 \%$ & & $\begin{array}{c}\text { Positive as early as } \\
\text { several days after } \\
\text { inoculation }\end{array}$ \\
& $\begin{array}{c}\text { Can detect as } \\
\text { few as } 135\end{array}$ & &
\end{tabular}

${ }^{*}$ Cost at Marshfield Clinic Laboratories.

HCV-ELISA, hepatitis C virus-enzyme-linked immunosorbent assay; HCV-RIBA, hepatitis C virus-recombinant immunoblot; HCV-PCR, hepatitis C virus-polymerase chain reaction. 

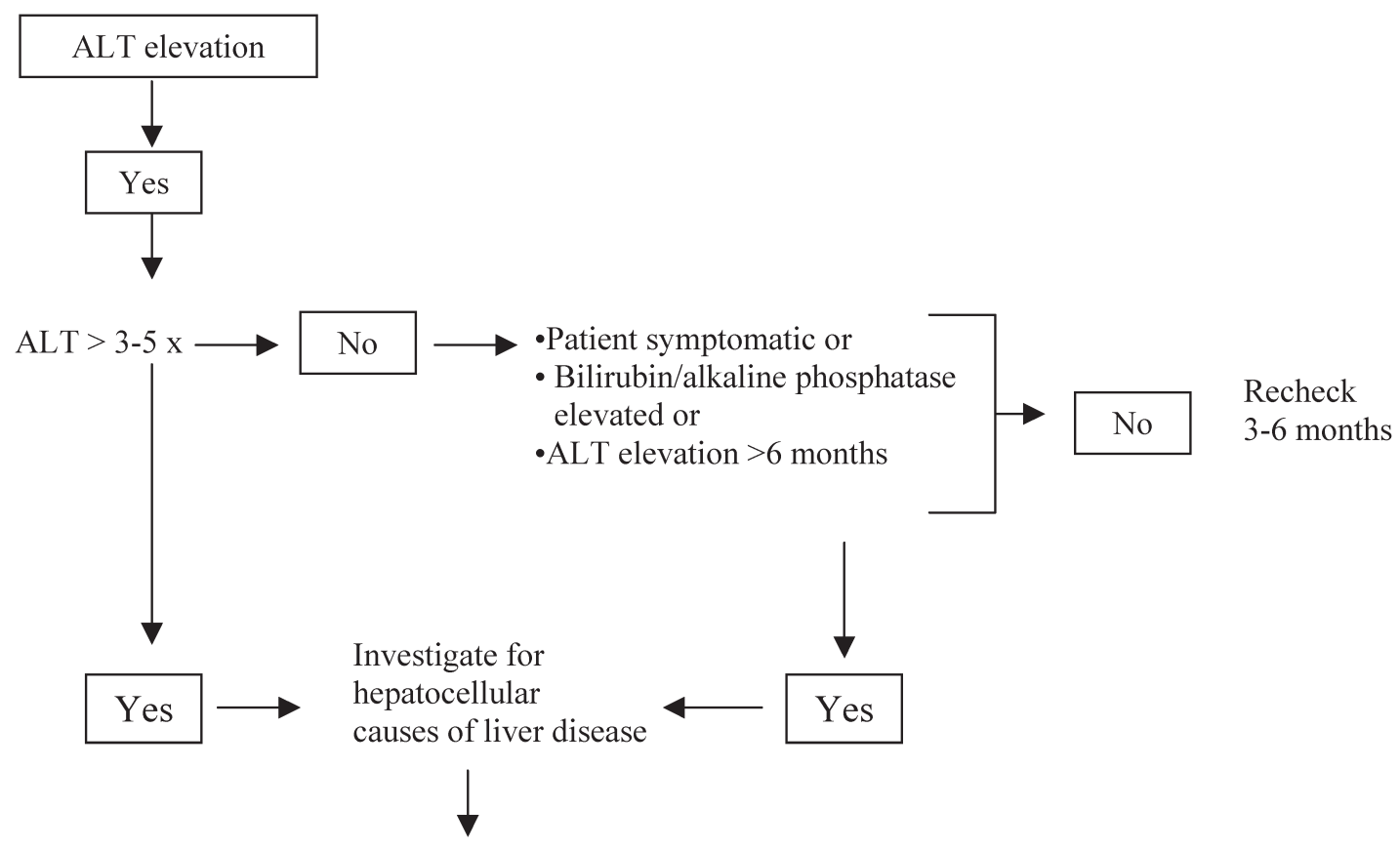

Viral hepatitis

Autoimmune hepatitis

Celiac disease

Wilson's disease

Hemochromatosis

Alpha-1-antitrypsin deficiency

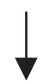

Liver ultrasound

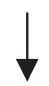

Consider liver biopsy

Figure 1. Algorithm for evaluating an elevation in alanine transaminase.

distinguish past from current HCV infection. Patients who have had previous exposures and recovered from $\mathrm{HCV}$ infection may remain anti-HCV positive for years. Patients who are anti-HCV positive by ELISA and have a negative RIBA are considered not to have ongoing HCV infection and do not require further evaluation. A RIBA test should be ordered after a positive screening for HCV by ELISA as a confirmatory test. Patients with indeterminate or positive RIBA results need confirmatory testing with the highly sensitive reverse transcription polymerase chain reaction (PCR) for HCV RNA. A repeat PCR test is recommended within 3 months for patients who are RIBA positive, despite a negative PCR result. ${ }^{4}$

HCV genotyping is useful for guiding the duration of therapy and predicting the likelihood of response, because the various genotypes have different susceptibilities to treatment. HCV genotyping is not currently used for diagnosis of infection.

\section{REFERENCES}

1. Moseley RH. Evaluation of abnormal liver function tests. Med Clin North Am 1996;80:887-906.

2. Green RM, Flamm S. AGA technical review on the evaluation of liver chemistry tests. Gastroenterology 2002;123:1367-1384.

3. Pratt DS, Kaplan MM. Evaluation of abnormal liver-enzyme results in asymptomatic patients. N Engl J Med 2000;342:1266-1271.

4. Dufour DR, Lott JA, Nolte FS, Gretch DR, Koff RS, Seeff LB. Diagnosis and monitoring of hepatic injury. II. Recommendations for use of laboratory tests in screening, diagnosis, and monitoring. Clin Chem 2000;46:2050-2068.

5. Kundrotas LW, Clement DJ. Serum alanine aminotransferase (ALT) elevation in asymptomatic US Air Force basic trainee blood donors. Dig Dis Sci 1993;38:2145-2150.

6. Mathiesen UL, Franzen LE, Fryden A, Foberg U, Bodemar G. The clinical significance of slightly to moderately increased liver transaminase values in asymptomatic patients. Scand J Gastroenterol 1999;34:85-91.

7. Lok AS, Gunaratnam NT. Diagnosis of hepatitis C. Hepatology 1997;26(3 Suppl 1):48S-56S. 